\title{
Population and spatial breeding dynamics of a Critically Endangered Oriental White-backed Vulture Gyps bengalensis colony in Sindh Province, Pakistan
}

\author{
CAMPBELL MURN, UZMA SAEED, UZMA KHAN and SHAHID IQBAL
}

\section{Summary}

The Critically Endangered Oriental White-backed Vulture Gyps bengalensis has declined across most of its range by over $95 \%$ since the mid-1990s. The primary cause of the decline and an ongoing threat is the ingestion by vultures of livestock carcasses containing residues of nonsteroidal anti-inflammatory drugs, principally diclofenac. Recent surveys in Pakistan during 2010 and 2011 revealed very few vultures or nests, particularly of White-backed Vultures. From 2011 in the Tharparkar District of Sindh Province we monitored a colony of Oriental White-backed Vultures. Between 2011 and 2014 the number of active nests in this colony increased from 11 to 34 while nest density decreased from 13.7 to 9.2 nests $\mathrm{km}^{-2}$, suggesting that the colony is expanding. We conclude that the rate of increase is being subsidised by immigration, as the population demographics do not support the observed rate of increase in nests. We present the first analysis of spatial breeding dynamics for the Oriental White-backed Vulture and describe how a clustered pattern of nest trees in colonies supports a highly clustered pattern of nests. The spatial pattern of nests relies on both the distribution of trees and the ability of trees to support more than one nest. These results highlight that the preservation of larger nest trees and the sustainable management of timber resources are essential components for the conservation management of this species. We emphasise the high importance of this colony and a nearby Long-billed Vulture Gyps indicus colony in this area of Pakistan. Recommended conservation management actions include the continuation of a Vulture Safe Zone established in 2012, measuring breeding success, assessing dispersal and determining the impact of mortality on these populations.

\section{Introduction}

Population declines of Gyps vulture species across south Asia have been well-documented since they were first reported in 1999 (Prakash 1999, Prakash et al. 2003, Gilbert et al. 2006). As a result of these declines, the Oriental White-backed Vulture Gyps bengalensis, Long-billed Vulture Gyps indicus and the Slender-billed Vulture Gyps tenuirostris are all listed as 'Critically Endangered' (IUCN 2013).

The primary cause of these declines was the ingestion by vultures of livestock carcasses that had been recently treated with non-steroidal anti-inflammatory drugs (NSAIDs), principally diclofenac (Oaks et al. 2004, Green et al. 2004). Since the identification of NSAIDs as the primary cause of vulture declines in south Asia, a range of conservation efforts have focused on the recovery of vulture populations. These have included the banning of veterinary diclofenac (Pain et al. 2008), 
the establishment of conservation breeding centres (Murn et al. 2008, Bowden et al. 2012), the identification of safe alternative veterinary drugs (Swarup et al. 2007), efforts to remove diclofenac from the environment (Swan et al. 2006, Cuthbert et al. 2011) and the establishment of Vulture Safe Zones (Chaudhary et al. 2012), which provide 'safe' food for vultures in designated areas and also use advocacy and lobbying to remove diclofenac from veterinary use and subsequently livestock carcasses. There is evidence that these conservation efforts are beginning to be successful, with residues of diclofenac in livestock carcasses having fallen in some areas (Cuthbert et al. 2011). As a result, the rate of population decline for Oriental White-backed Vultures has slowed, and for Long-billed Vultures, reversed (Prakash et al. 2012, Chaudhry et al. 2012).

In Pakistan, the Oriental White-backed Vulture has been monitored extensively in some areas, particularly Punjab Province (Gilbert et al. 2006, 2007, Arshad et al. 2009). The species is known to occur in Sindh Province, in south-east Pakistan (Roberts 1991), but there is relatively little reported information about the species from there. Gilbert et al. (2004) recorded nests in several areas of Sindh, primarily in eastern and north-eastern districts, but numbers of nests were low $(<10)$. The range map for the species (Roberts 1991) does not extend to the far south-east of Sindh, in the Nagarparkar area of Tharparkar District, which is adjacent to the Great Rann of Kutch in the south-eastern corner of the province.

Through local fieldwork starting in 2009 and during a national survey of vultures in Pakistan in 2011, a small breeding colony of Oriental White-backed Vultures was recorded in the south-eastern corner of Tharparkar District in Sindh Province. This paper provides the first description of this previously unreported colony of Oriental White-backed Vultures. Based on fieldwork from 2011 to 2014 we describe the population size and associated spatial dynamics of the breeding colony, and discuss the future conservation of this colony.

\section{Study area and methods}

The study was carried out in the south-eastern corner of Tharparkar District, Sindh Province, approximately $10 \mathrm{~km}$ north-west of the Kharoonjar Hills $\left(\mathrm{N}_{24} 4^{\circ} 2 \mathrm{O}^{\prime} \mathrm{E}_{70^{\circ}} 43^{\prime}\right)$ and the town of Nagarparkar (Figure I). The region is arid and generally flat with areas of relief characterised by isolated granite outcrop hills. The loam soils and low rainfall provide for the main land-uses of low-density perennial livestock grazing and non-irrigated crop fields. Habitat is dry open scrub with scattered trees characterised primarily by stands of kandi Prosopis cineraria.

Annual surveys of the study area were conducted from 2 February to 17 April 2011; 1 April to 15 April 2012; I March to 15 March 2013, and 24 January to 17 February 2014. Nests were located by thorough searches of the study area, by following flying birds to their roost locations in a $4 \times 4$ vehicle at the end of each day and by paying particular attention to areas with larger trees. Local residents were questioned for information about the locations of vulture nests or roosts. For roost sites that were located, numbers of birds were counted on four occasions during the annual survey visits. The number of roosting birds was counted between 15 hoo and 18 hoo and then again early the following morning at the same roost site. All positions were logged using a hand-held GPS. Nests were recorded as occupied if adults were in attendance or a chick was in the nest, but measures of breeding productivity were not possible because the survey was conducted only once each breeding season. Nest trees were identified with spray-painted numbers to avoid double-counting and for inter-year reference. The height of each nest tree was estimated by eye.

Nest density (nests $\mathrm{km}^{-2}$ ) was calculated each year by dividing the number of nests by their spatial extent $\left(\mathrm{km}^{2}\right)$, which was determined as the area of a polygon containing all occupied nests. Oriental White-backed Vultures nest in colonies (Roberts 1991) and clusters of nests are a feature of the species (BirdLife International 2014). To assess the spatial pattern of nests and change between years we calculated the mean nearest-neighbour distance (NND) between all nests each year. However, because more than one breeding pair of White-backed Vultures can nest in the same tree, we calculated two nearest-neighbour metrics: (a) the distance between 


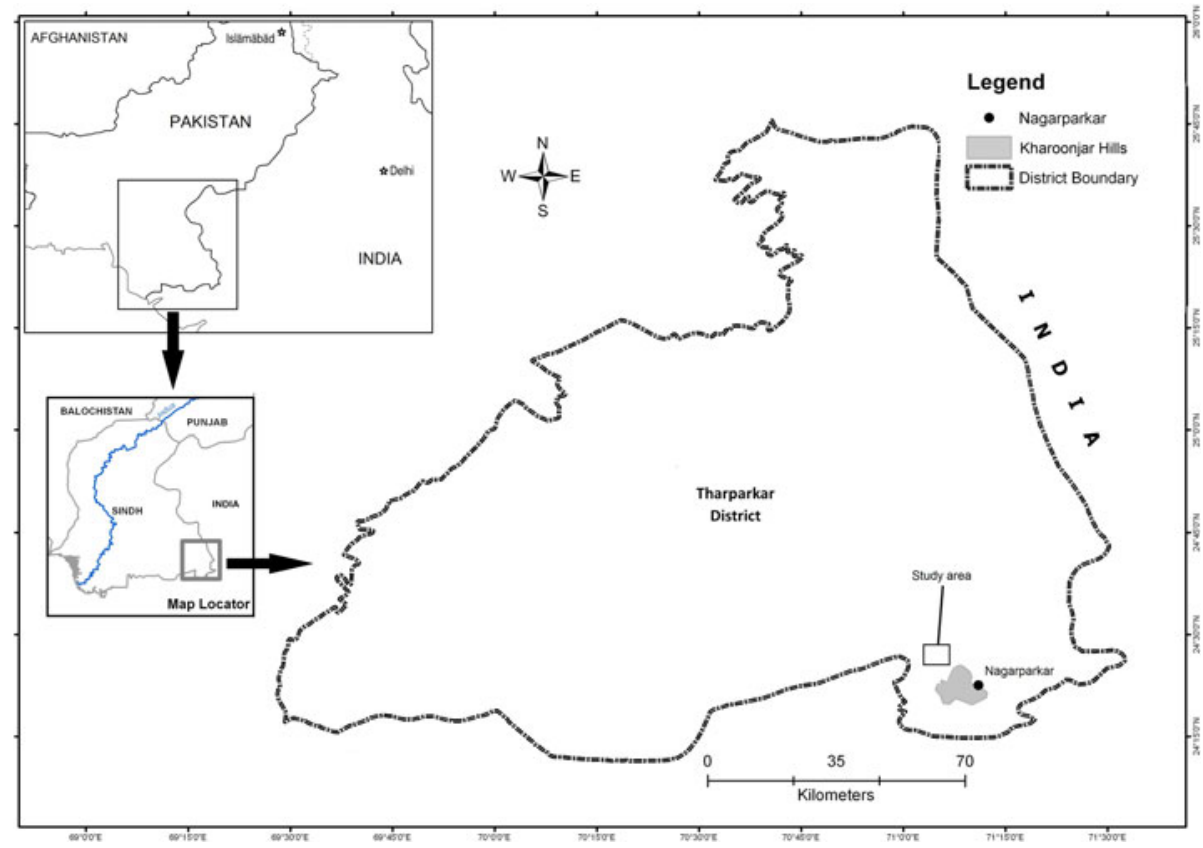

Figure 1. Location of the study area near Nagarparkar town in southeast Sindh Province, Pakistan.

trees with nests (tree-NND), and (b) the distance between nests (nest-NND), using a predetermined 3-m NND for nests in the same tree.

Mean NND (tree or nest) on its own is insufficient to describe differences between spatial point patterns because two point patterns with different characteristics might have the same mean NND. To assess the degree of clustering we calculated the ratio of the geometric mean (GMR) to the arithmetic mean of the squared NND (Brown and Rothery 1993, Murn et al. 2013). The maximum value for this statistic (GMR) is unity, where all NNDs are equal. Complete spatial randomness occurs at GMR $=0.5$, whilst the minimum GMR value is unbounded. Therefore, increasingly smaller GMR values represent spatial patterns of nests with tighter clustering. We chose this metric because the spatial extent of the nests was discrete and as a result, there were no outlier nests that would have disproportionately affected the GMR. Similarly, the discrete spatial extent of the nests negated the need to account for edge effects - the existence of unknown nests marginally outside the study area - when measuring nearest-neighbour distances because the colony nests were the only nests in the entire study area. We expected mean values for tree-NND and nest-NND to reflect density, such that mean NND would decrease with increasing density and vice versa, but we held no $a$ priori assumptions about the degree of nest clustering in relation to nest numbers or density.

NND data were transformed where necessary to stabilise variance and checked with Anderson-Darling tests, after which one way ANOVA was used for comparison of NNDs between years. Data that did not conform to parametric assumptions after transformation were subject to Kruskal-Wallis tests. Homogeneity of variance in sample ranks was checked with Levene's test. Tests were performed in Minitab 16.

\section{Results}

Nests were located mainly in kandi Prosopis cineraria trees (all nests in 2011 and 2012), but neem Azadirachta indica (two nests in 2013), rohida Tecomella undulata and tamarind 


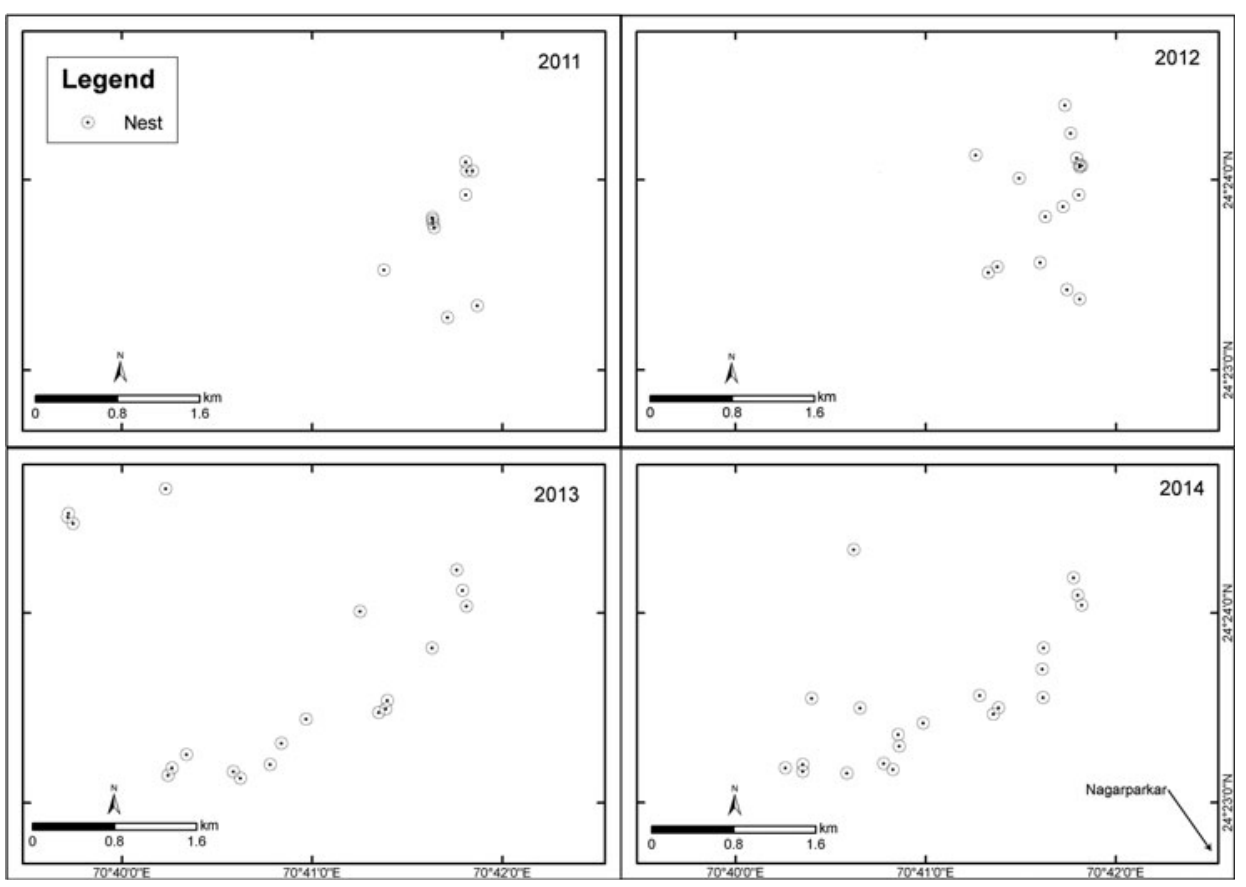

Figure 2. The spatial pattern of nest trees in an Oriental White-backed Vulture colony, 2011 to 2014, Sindh Province, Pakistan.

Tamarindus indica (one nest each in 2014) were also used. Nest trees were larger than surrounding trees and had a mean height of $11.6(\mathrm{SD} \pm 2) \mathrm{m}$. A maximum of seven nests in one tree was recorded, and this large tree was located within one of the villages in the study area. The distribution of the nests across the four years was dynamic and although it was not possible to identify birds individually, several nests were occupied in each of the four years, whilst new nests were made each year (Figure 2).

The number of recorded nests increased each year and tripled during the study period (Table 1 ). The marked reduction in density from 2012 to 2013 , despite a $40 \%$ increase in the number of active nests, reflects the spatial expansion of the colony (Figure 2). The number of trees containing more than one nest increased rapidly from 10.5\% of trees in 2012 to $23.5 \%$ of trees in 2014 , but despite the tree containing seven nests, the mean number of nests per multi-nest tree remained near 2.5 each year $\left(\right.$ mean $=2.55$ nests tree ${ }^{-1}$, range $\left.=2.4-2.75\right)$.

Table 1. Number of nests and some spatial characteristics of an Oriental White-backed Vulture Gyps bengalensis colony in Tharparkar District, Sindh, Pakistan.

\begin{tabular}{lllllll}
\hline Year & $\begin{array}{l}\text { Number of } \\
\text { nests }\end{array}$ & $\begin{array}{l}\text { Colony area } \\
\left(\mathrm{km}^{2}\right)\end{array}$ & $\begin{array}{l}\text { Density } \\
(\text { nests km-2) }\end{array}$ & $\begin{array}{l}\text { Mean NND* } \\
( \pm \mathrm{SD})-\text { Tree }(\mathrm{m})\end{array}$ & $\begin{array}{l}\text { Mean NND* } \\
( \pm \mathrm{SD})-\text { Nest }(\mathrm{m})\end{array}$ & $\begin{array}{l}\text { Number of } \\
\text { multi-nest } \\
\text { trees (max } \\
\text { nests per tree })\end{array}$ \\
\hline 2011 & 11 & 0.8 & 13.75 & $157( \pm 182)$ & $157( \pm 182)$ & 0 \\
2012 & 19 & 1.4 & 13.6 & $159( \pm 137)$ & $147( \pm 146)$ & $2(3)$ \\
2013 & 27 & 8.0 & 3.4 & $256( \pm 278)$ & $136( \pm 278)$ & $5(4)$ \\
2014 & 34 & 3.7 & 9.2 & $271( \pm 329)$ & $56( \pm 94)$ & $8(7)$ \\
\hline
\end{tabular}

${ }^{*}$ Nearest-neighbour distance 
The two nearest-neighbour metrics revealed different aspects of the growth of the colony, and neither was correlated with colony area or nest density. Mean tree-NND increased each year and was significantly different between years (one-way ANOVA $F_{3,87}=2.81, P=0.04$ ), possibly reflecting the decreasing density. Mean nest-NND decreased each year (Kruskal-Wallis $H=11.92, P=0.008$ ), which is most likely a function of the increasing number of trees with multiple nests. Across all years, mean tree-NND was $230 \mathrm{~m}( \pm \mathrm{SE} 28 \mathrm{~m})$ and mean nest-NND was $110 \mathrm{~m}( \pm \mathrm{SE} 20 \mathrm{~m})$.

In each year, the spatial pattern of trees with nests was clustered (GMR < 0.25). But despite increasing numbers of nests, increasing mean tree-NND and decreasing density, the GMR for nest trees remained in the region of 0.20 between 2012 and 2014 (Figure 3).

Maximum roost counts during each survey period were 39 birds in 2011 (one site located near the active nests), 102 birds in 2013 (two sites) and 145 birds in 2014 (two sites). No roost counts were conducted in 2012 . The roost sites were in the same location each day, and did not change between years. In 2014 the approximate age proportions were $60 \%$ adults, $14 \%$ sub-adults and $25 \%$ juveniles. Assuming that I) one adult of a breeding pair ( 34 pairs) will remain at an active nest overnight; 2 ) the other breeding adult (34 birds) joins a communal roost and 3 ) that non-breeding adults (approximately 54 birds) and immature birds ( 57 birds) were also part of communal roosts, we estimate that the population of this colony during the 2014 breeding season was approximately 180 individuals. Thus, approximately $30 \%$ of the adult population are estimated to be non-breeding birds.

Nine dead vultures were found between 2011 and 2014 (Table 2), although systematic surveys to locate dead birds were not conducted. The cause of death for these birds could not be established due to advanced decomposition of the bodies.

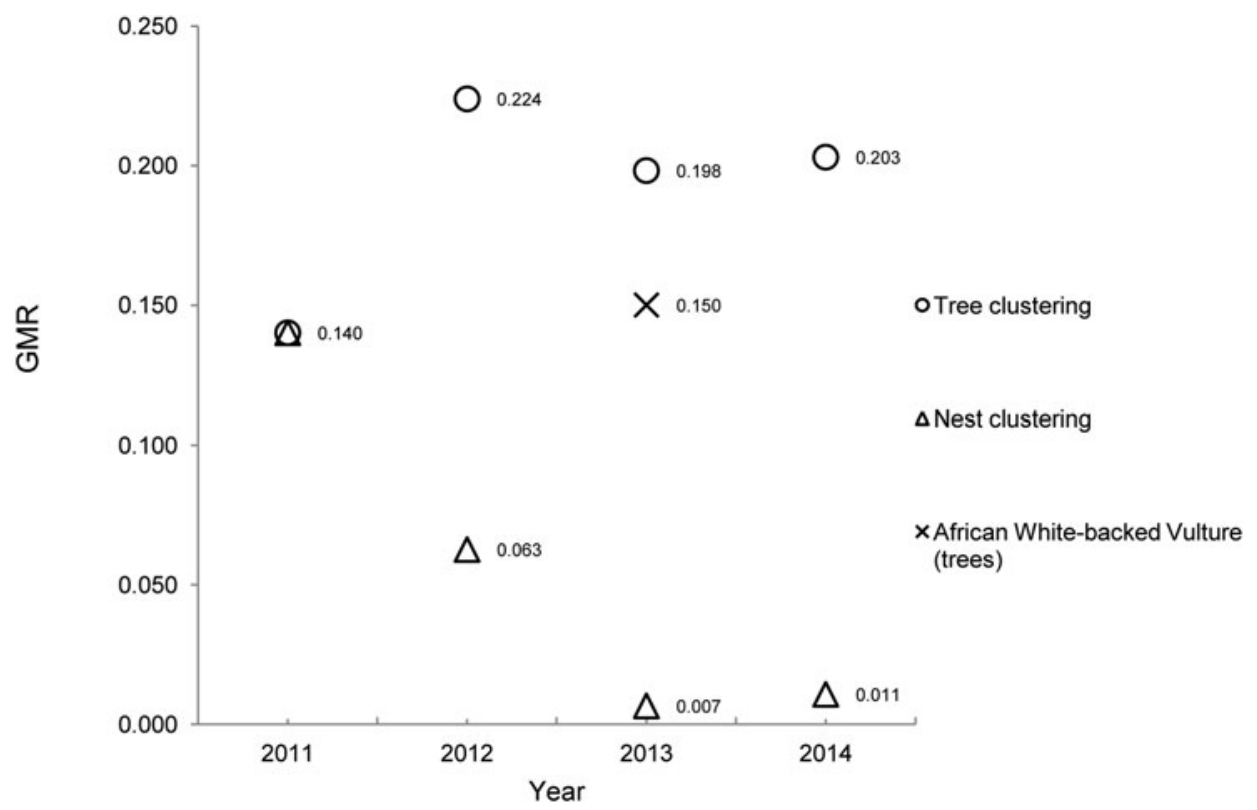

Figure 3. Spatial dynamics of an Oriental White-backed Vulture breeding colony over four years. The clustering characteristics of nest trees and nests are analysed as spatial point patterns. GMR is the extent of clustering; lower values occur with tighter clustering of a spatial point pattern. A similar tree-nesting vulture species, the African White-backed Vulture Gyps africanus, is provided for comparison. 
Table 2. Details of dead vultures found during breeding colony surveys of Oriental White-backed Vultures Gyps bengalensis in Tharparkar District, Sindh, Pakistan.

\begin{tabular}{llll}
\hline Date & Remains & Age & Found \\
\hline $5 / 2 / 11$ & Desiccated carcass & Adult & Hanging from tree \\
$19 / 2 / 11$ & Feather remains & Adult & On the ground \\
$16 / 3 / 13$ & Desiccated carcass & Pre-fledged nestling & Ground below nest tree \\
$16 / 3 / 13$ & Desiccated carcass & Pre-fledged nestling & Ground below nest tree \\
$15 / 3 / 13$ & Partial remains & Pre-fledged nestling & In nest \\
$15 / 3 / 13$ & Desiccated carcass & Juvenile & On the ground \\
$16 / 3 / 13$ & Desiccated carcass & Adult & In nest \\
$16 / 3 / 13$ & Partial remains & Adult & In nest \\
$7 / 2 / 14$ & Desiccated carcass & Adult & Ground below nest tree \\
\hline
\end{tabular}

\section{Discussion}

The nest densities in 2011 and 2012 (Table 1 ) are comparable with and slightly higher than pre-decline (1980s) densities of 12.2 nests $\mathrm{km}^{-2}$ recorded in Keoladeo National Park, India (Prakash and Rahmani 1999), higher than pre-decline densities of $2.5-5$ nests $\mathrm{km}^{-2}$ reported from coastal mangrove areas of southern Bangladesh (Sarker 1987) and approaching the higher densities of 15 nests $\mathrm{km}^{-2}$ reported for Changa Manga forestry plantation in Punjab Province near Lahore (Gilbert et al. 2002). This last population was experiencing rapid decline from diclofenac poisoning during the monitoring period (Gilbert et al. 2006), and so nest densities could have been lower than a potential maximum. Apart from differences in habitat (arid Nagarparkar, wetland-dominated Keoladeo, coastal mangroves Sundarbans, and forest plantation Changa Manga), the manner in which spatial extent of the breeding areas was calculated and the availability of trees in each study area may provide another explanation for these variations in nest density. Regardless of the reasons for this variation, the nest densities found in our study are within the range of densities reported for a number of different locations prior to, and during, the decline of south Asian vulture populations (Prakash and Rahmani 1999, Sarker 1987, Gilbert et al. 2002). However, none of these densities even remotely approaches historical accounts for this species of 'up to 15 nests in one tree' and 100 nests in a $250 \mathrm{~m}$ diameter circle (Hume and Oates 1889-1890), although Roberts (1991) describes up to six nests occurring in one tree.

Despite an increasing mean tree-NND each year and a moderate level of nest tree clustering (Figure 3), the decreasing mean nest-NND and the increased clustering of nests in a growing breeding population highlights the strong colonial tendencies of this species. In comparison, there are two other tree-nesting Gyps vultures, the Slender-billed Vulture and the African White-backed Vulture Gyps africanus. We are unaware of any nearest-neighbour analyses for the relatively less-studied Slender-billed Vulture, so a direct comparison is not possible. However the species is reported to nest singly (one breeding pair per tree) in relatively small colonies of 7-8 pairs (BirdLife International 2014) although more than one nest in a tree has been recorded occasionally (Mathews 1918).

African White-backed Vultures nest in what have been termed 'loose colonies' (Mundy et al. 1992), usually with only one breeding pair per nest tree. In savanna areas (i.e. not linear riparian nests) a mean NND distance has been reported as $697 \mathrm{~m}( \pm \mathrm{SD} 913 \mathrm{~m}, n=217)$ with a GMR of 0.15 (Murn et al. 2013). Although the mean tree-NND for African White-backed Vultures is significantly higher $(\mathrm{T}=6.85, \mathrm{P}<\mathrm{O}$.001) than the Oriental White-backed Vultures in this study, the African species still shows a tendency for clustered nest trees (Figure 3). Given that a tightly-clustered pattern (GMR O.OI) of Oriental White-backed Vulture nests can occur in nest trees that are moderately clustered (GMR $\sim 0.20)$, it is likely that the colonial-nesting and clustering tendencies of this species reflect the sufficient availability of trees large enough 
to support multiple nests. Although not all trees in a colony will be large enough or of suitable canopy structure to accommodate more than one nest, a characteristic spatial arrangement (i.e. clustering) of nests may occur at a threshold that is related to the availability of suitable trees. For example, Satheesan (1995) reported large (pre-decline) numbers of roosting Oriental White-backed Vultures on very large trees in Agra City, India, but did not record any more than three nests in one tree in the same area. Similarly, in post-decline breeding populations, numbers of nests per tree are still in the range of $1-3$ (Baral et al. 2005, Roy and Shastri 2013). It is therefore possible that the tight nest-clustering characteristics favoured by this species can be achieved with a relatively small number of nests per tree if the available trees are of a suitable size, structure and spatial pattern (GMR 0.2). This may suggest that an optimum level of nest tree clustering exists to support a range of colony sizes and nest densities.

\section{Monitoring and conservation implications}

Despite not being able to assess breeding productivity we do consider that, given the limitations of an annual survey, the number of nests recorded each year was representative of the breeding colony size for two reasons. Firstly, the number of inactive nests was low, suggesting that the number of breeding pairs that started a breeding attempt and failed is also low. Secondly, the survey dates of January to April each year covered the main part of the breeding season; most breeding pairs that did make an attempt would have made nests and been incubating, whilst early breeders would still be either in late stage incubation or with a chick in the nest.

Although it is encouraging that the number of recorded nests has tripled since 2011, this is tempered by a slowing of the rate at which the colony is growing (Table 1 ) and the fact that a number of queries and research priorities remain. Firstly, it is unknown from where the additional breeding birds have arrived. In the absence of additive mortality, Oriental White-backed Vultures are generally long-lived birds with an estimated generation time of 16 years (BirdLife International 2014). Using a conservative estimate of birds not reproducing until their fourth year, the increase in the breeding population observed in our study has almost certainly been enhanced by immigration, as the demographics of such a small population with this length of generation time do not support the observed rapid increase in the number of nests. It is also possible however, that following the 2006 ban on veterinary diclofenac, there has been an increasing rate of survival to maturity for age cohorts hatched post-2006, and that these birds are the source of the additional birds.

Secondly, the risks and effects of mortality (such as NSAID poisoning) need to be assessed. Although a number of dead birds were found without a concerted search effort, four of the nine birds were of pre-fledging or recently-fledged age, and high mortality in this age group of vultures is not unusual (Mundy et al. 1992). The five dead adults that were found offer more cause for concern, as adult survival is one of the most sensitive demographic parameters for vultures (Oro et al. 2008, Margalida et al. 2014) and suggests that this age class is potentially still at risk. Even with the goal of complete removal of diclofenac and other harmful non-steroidal anti-inflammatory drugs from the environment, it is possible that residual quantities of diclofenac remain in livestock carcasses and are a threat to vultures. The establishment of a Vulture Safe Zone (VSZ) in the study area in 2012 saw the beginning of a new phase of environmental monitoring and conservation to address this. Across the approximately $8,000 \mathrm{~km}^{2}$ $\mathrm{VSZ}$, a range of activities such as livestock health camps, awareness-raising sessions in villages and consultations with veterinary dispensaries are all aimed at highlighting the risks to vultures from diclofenac and emphasising the need to maintain the ban on its use in livestock.

Thirdly, an important next step in the monitoring of this colony is to determine breeding success. Comparing breeding success with pre-decline populations (Prakash 1999) and those that were suffering acute mortality from diclofenac poisoning (Gilbert et al. 2002) could offer an indication of what levels of additive mortality exist for this population. Similarly, comparison of 
breeding productivity with the nearby colony of Long-billed Vultures (Chaudhry et al. 2012) will be important to see if the colonies are both (or neither) affected by similar rates of mortality.

Finally, dispersal behaviour of birds from this population must also be assessed. Oriental White-backed Vultures can range over vast distances (Gilbert et al. 2007), so it is not unlikely that birds may be dispersing across a wide area, in the same way that birds may have arrived to the Nagarparkar colony from adjacent areas such as Gujarat in India.

The description of breeding colony spatial dynamics outlined here has important implications for the conservation of Oriental White-backed Vultures, particularly in areas (such as our study area or other arid zone areas) where the number of suitable nest trees may be limited and a lack of suitable trees may limit clustering of nests and hence potential colony size. Large trees in particular should be preserved and protected, whilst conservation management and sustainable harvesting of timber for fuel stock and/or building materials can be focused on smaller trees. Where nest trees do not appear to be a limiting factor, Oriental White-backed Vulture colonies can reach very high numbers such as the 700-80o nests recorded at Changa Manga (Gilbert et al. 2002), although the number of multi-nest trees and extent of nest clustering has not been reported for this colony.

Based on a recent national survey of vultures (Iqbal et al. 2011), this colony of Oriental White-backed Vultures is currently the only known extant breeding population in Pakistan, in addition to being previously unreported in the general literature (Roberts 1991, Gilbert et al. 2004, Chaudhry et al. 2012 ). Lending additional importance to our study area is the nearby colony of Long-billed Vultures breeding in the Kharoonjar Hills (Chaudhry et al. 2012), which is the only breeding colony of this species recorded for Pakistan (Roberts 1991). The Vulture Safe Zone in Sindh Province is thus a major step towards the long-term conservation of these two species in the south Asian region.

Diclofenac is not the only NSAID that is toxic to vultures - there are other veterinary drugs that represent a threat such as ketoprofen (Naidoo et al. 2010), aceclofenac (Sharma 2012) and flunixin (Zorrilla et al. 2014), which are all still legal and in circulation. In this regard, we support fully the continued development and maintenance of Vulture Safe Zones in south Asia as a means of ongoing progression towards the conservation objective of restoring viable populations of vultures to areas where they once occurred. However, the long-term conservation value of a Vulture Safe Zone will be reduced if there are limited opportunities for vultures to nest in the spatial patterns that optimise the dynamics of their breeding colonies. Based on the results presented here, and in addition to the removal of unsafe veterinary drugs, a key component of Vulture Safe Zone work should be the preservation of nest tree distributions that can support large colonies of clustered nests of Oriental White-backed Vultures.

\section{Acknowledgements}

U.S. Fish and Wildlife Service for a grant enabling establishment of Vulture Safe Zone, the Parkar Foundation for continued advocacy in the Sindh Vulture Safe Zone. A grant from the National Birds of Prey Trust helped fund the 2011 national survey and WWF-Pakistan's small grants programme supported the 2014 breeding season survey. Muhammad Humza and Irfan Ashraf from WWF-Pakistan's GIS laboratory provided mapping support. Antoni Margalida and two other reviewers provided feedback that improved the manuscript.

\section{References}

Arshad, M., Chaudhry, M. J. I. and Wink, M. (2009) High mortality and sex ratio imbalance in a critically declining Oriental White-backed Vulture population (Gyps bengalensis) in Pakistan. J. Ornithol. 150: 495-503.

Baral, N., Gautam, R. and Tamang, B. (2005) Population status and breeding ecology of 
White-rumped Vulture Gyps bengalensis in Rampur Valley, Nepal. Forktail 21: 87-91.

BirdLife International (2014) Species factsheet: Gyps bengalensis. Downloaded from www. birdlife.org January 2014.

Bowden, C. G. R., Prakash, V., Ranade, S., Routh, A., Jakatt, R. D., Cuthbert, R., Rahmani, A. R., Green, R. E., Prakash, N. and Parry-Jones, J. (2012) Conservation breeding for the future release of the critically endangered Asian Gyps vultures progress of the programme in south Asia and why it is so important. J. Bombay Nat. Hist.Soc. 109: 43-45.

Brown, D. and Rothery, P. (1993) Models in biology: mathematics, statistics and computing. Chichester, UK: John Wiley and Sons.

Chaudhary, A., Subedi, T. R., Giri, J. B., Baral, H. S., Bidari, B., Subedi, H., Chaudhary, B., Chaudhary, I., Paudel, K. and Cuthbert, R. (2012) Population trends of Critically Endangered Gyps vultures in the lowlands of Nepal. Bird Conserv. Internatn. 22: 270-278.

Chaudhry, M. J. I., Ogada, D. L., Malik, R. N., Virani, M. Z. and Giovanni, M. D. (2012) First evidence that populations of critically endangered Long-billed Vulture Gyps indicus in Pakistan have increased following the ban of the toxic veterinary drug diclofenac in south Asia. Bird Conserv. Internatn. 22: 389-397.

Cuthbert, R., Taggart, M. A., Prakash, V., Swarup, D., Suchitra, U., Mateo, R., Chakraborty, S. S., Deori, P. and Green, R. E. (2011) Effectiveness of action in India to reduce exposure of Gyps vultures to the toxic veterinary drug diclofenac. PLOS ONE 6: e19069.

Gilbert, M., Virani, M. Z., Watson, R. T., Oaks, J. L., Benson, P. C., Khan, A. A., Ahmed, S., Chaudhry, J., Arshad, M., Mahmood, S. and Shah, Q. A. (2002) Breeding and mortallity of Oriental White-backed Vulture Gyps bengalensis in Punjab Province, Pakistan. Bird Conserv. Internatn. 12: 311-326.

Gilbert, M., Virani, M. Z., Watson, R. T., Oaks, J. L., Benson, P. C., Khan, A. A., Ahmed, S., Chaudhry, M. J. I., Arshad, M., Mahmood, S. and Shah, Q. A. (2004) The status and decline of vultures in the provinces of Punjab and Sind, Pakistan: a 2003 update. Pp. $311-326$ in R. D. Chancellor and B.-U. Meyburg, eds. Raptors worldwide. Berlin, Germany: World Working Group on Birds of Prey and Owls. Gilbert, M., Watson, R. T., Ahmed, S., Asim, M. and Johnson, J. A. (2007) Vulture restaurants and their role in reducing diclofenac exposure in Asian vultures. Bird Conserv. Internatn. 17: 63-77.

Gilbert, M., Watson, R. T., Virani, M. Z., Oaks, J. L., Ahmed, S., Chaudhry, M. J. I., Arshad, M., Mahmood, S., Ali, A. and Khan, A. A. (2006) Rapid population declines and mortality clusters in three Oriental whitebacked vulture Gyps bengalensis colonies in Pakistan due to diclofenac poisoning. Oryx 40: 388-399.

Green, R. E., Newton, I., Shultz, S., Cunningham, A. A., Gilbert, M., Pain, D. J. and Prakash, V. (2004) Diclofenac poisoning as a cause of vulture population declines across the Indian subcontinent. J. Appl. Ecol. 41: 793-800.

Hume, A. O. and Oates, E. W. (1889-189o) Nests and eggs of Indian birds. London, UK: R. H. Porter.

Iqbal, S., Khan, U. and Murn, C. (2011) Vulture population and status survey, Pakistan. Unpublished internal report. Lahore: WWFPakistan. II pp.

IUCN (2013) IUCN Red List of Threatened Species. Version 2012.1. Downloaded from www.iucnredlist.org January 2014.

Margalidia, A., Colomer, M. A. and Oro, D. (2014) Man-induced activities modify demographic parameters in a long-lived species: effects of poisoning and health policies. Ecol. Applic. 24: 436-444.

Mathews, W. H. (1918) Note on the Indian Long-billed Vulture. J. Bombay Nat. Hist. Soc. 26: 287 .

Mundy, P., Butchart, D., Ledger, J. and Piper, S. (1992) The vultures of Africa. London, UK: Academic Press.

Murn, C., Combrink, L., Ronaldson, G. S., Thompson, C. and Botha, A. (2013) Population estimates of three vulture species in Kruger National Park, South Africa. Ostrich 84: 1-9.

Murn, C., Khan, U. and Farid, F. (2008) Vulture populations in Pakistan and the 
Gyps Vulture Restoration Project. Vulture News 58: 35-43.

Naidoo, V., Wolter, K., Cromarty, D., Diekmann, M., Duncan, N., Meharg, A., Taggart, M. A., Venter, L. and Cuthbert, R. (2010) Toxicity of non-steroidal antiinflammatory drugs to Gyps vultures: a new threat from ketoprofen. Biol.Lett. 6: 339-341.

Oaks, J. L., Gilbert, M., Virani, M. Z., Watson, R. T., Meteyer, C. U., Rideout, B. A., Shivaprasad, H. L., Ahmed, S., Chaudhry, M. J. I., Arshad, M., Mahmood, S., Ali, A. and Khan, A. A. (2004) Diclofenac residues as the cause of vulture population decline in Pakistan. Nature 427: 630-633.

Oro, D., Margalida, A., Carrete, M., Heredia, R. and Donázar, J. A. (2008) Testing the goodness of supplementary feeding to enhance population viability in an endangered vulture. PLOS ONE 3(12): e4084.

Pain, D. J., Bowden, C. G. R., Cunningham, A. A., Cuthbert, R., Das, D., Gilbert, M., Jakati, R., Jhala, Y., Khan, A. A., Naidoo, V., Oaks, J. L., Parry-Jones, J., Prakash, V., Rahmani, A., Ranade, S., Baral, H. S., Senacha, K. R., Saravanan, S., Shah, N., Swan, G., Swarup, D., Taggart, M. A., Watson, R. T., Virani, M. Z., Wolter, K. and Green, R. E. (2008) The race to prevent the extinction of South Asian vultures. Bird Conserv. Internatn. 18: $\mathrm{S}_{30}-\mathrm{S}_{4} 8$.

Prakash, V. (1999) Status of vultures in Keoladeo National Park, Bharatpur, Rajasthan, with special reference to population crash in Gyps species. J. Bombay Nat. Hist.Soc. 96: 365-378.

Prakash, V. and Rahmani, A. R. (1999) Notes about the decline of Indian vultures, with particular reference to Keoladeo National Park. Vulture News 41: 6-13.

Prakash, V., Bishwakarma, M. C., Chaudhary, A., Cuthbert, R., Dave, R., Kulkarni, M., Kumar, S., Paudel, K., Ranade, S., Shringarpure, R. and Green, R. E. (2012) The population decline of Gyps vultures in India and Nepal has slowed since the veterinary use of diclofenac was banned. PLOS ONE 7: e49118.

Prakash, V., Pain, D. J., Cunningham, A. A., Donald, P. F., Prakash, N., Verma, A., Gargi, R., Sivakumar, S. and Rahmani, A. R. (2003) Catastrophic collapse of Indian white-backed Gyps bengalensis and long-billed Gyps indicus vulture populations. Biol.Conserv. 109: 381-390.

Roberts, T. J. (1991) The birds of Pakistan: Volume 1: Regional studies and nonPasseriformes. Karachi: Oxford University Press.

Roy, A. and Shastri, K. (2013) Nesting of the White-rumped Vulture Gyps bengalensis in Orchha Wildlife Sanctuary, Madhya Pradesh, India. J. Bombay Nat. Hist.Soc. 110: 6.

Sarker, S. U. (1987) The Indian Whitebacked Vulture in the Sundarbans, Bangladesh. Vulture News 18: 8-14.

Satheesan, S. M. (1995) Roost and nest trees preferred by Indian Whitebacked Vultures Pseudogyps bengalensis in Agra city and environs. Vulture News 32: 3-9.

Sharma, P. (2012) Aceclofenac as a potential threat to critically endangered vultures in India: a review. J. Raptor Res. 46: 314-318.

Swan, G., Naidoo, V., Cuthbert, R., Green, R. E., Pain, D. J., Swarup, D., Prakash, V., Taggart, M., Bekker, L., Das, D., Diekmann, J., Diekmann, M., Killian, E., Meharg, A., Patra, R. C., Saini, M. and Wolter, K. (2006) Removing the threat of diclofenac to critically endangered Asian vultures. PLoS Biol. 4: 395-402.

Swarup, D., Patra, R. C., Prakash, V., Cuthbert, R., Das, D., Avari, P., Pain, D. J., Green, R. E., Sharma, A. K., Saini, M., Das, D. and Taggart, M. (2007) Safety of meloxicam to critically endangered Gyps vultures and other scavenging birds in India. Anim.Conserv. 10: 192-198.

Zorrilla, I., Martinez, R., Taggart, M. A. and Richards, N. (2014) Suspected flunixin poisoning of a wild Eurasian Griffon Vulture in Spain. Conserv. Biol. doi: $10.1111 /$ cobi.12417. 


\section{CAMPBELL MURN*}

Hawk Conservancy Trust, Andover, Hampshire SP11 8DY, UK; and Centre for Wildlife Assessment and Conservation, School of Biological Sciences, University of Reading, Reading, Berkshire RG5 6AS, UK.

UZMA SAEED, UZMA KHAN, SHAHID IQBAL

WWF-Pakistan, Ferozepur Road, Lahore, 5460o, Pakistan.

*Author for correspondence; email: campbell@hawkconservancy.org

Received 30 April 2014; revision accepted 14 November 2014; Published online 16 December 2014 